\title{
Isolation and culture of human endometrial cells in a three-dimensional culture system
}

\author{
U. Bentin-Ley ${ }^{1}$, B. Pedersen ${ }^{2}$, S. Lindenberg ${ }^{3}$, J. Falck Larsen ${ }^{1}$, \\ L. Hamberger ${ }^{4}$ and T. Horn ${ }^{5}$ \\ ${ }^{1}$ Herlev Hospital, Department of Obstetrics and Gynaecology, University of Copenhagen, \\ DK 2730 Herlev, Denmark; ${ }^{2}$ Chromosome Laboratory, Section of Clinical Genetics, Department of \\ Obstetrics and Gynaecology, Rigshospitalet, University of Copenhagen, Blegdamsvej 9, DK 2100 \\ Copenhagen, Denmark; ${ }^{3}$ Frederiksberg Hospital, Department of Obstetrics and Gynaecology, University of \\ Copenhagen, DK 2000 Frederiksberg, Denmark; ${ }^{4}$ Department of Obstetrics and Gynaecology, University \\ of Göteborg, Sahlgrenska University Hospital, Sweden; and ${ }^{5}$ Herlev Hospital, Department of Pathology, \\ University of Copenhagen, DK 2730 Herlev, Denmark
}

A cell culture system was established in which endometrial stromal cells were embedded in a collagen matrix and separated from the endometrial epithelium by basement membrane material (Matrigel). The epithelium, seeded on top of the collagen matrix, grew in a monolayer. The cultures were evaluated by light microscopy and transmission and scanning electron microscopy. Light and transmission electron microscopy indicated a polarized columnar epithelium in monolayer with basally positioned nuclei. Scanning electron microscopy revealed a confluent epithelium with an abundance of microvilli and cilia, as well as pinopodes on the apical surface. Immunohistochemical staining for cytokeratin confirmed the epithelial origin of the surface cells, and staining for human collagen IV demonstrated its presence underneath the epithelial cells. This culture system represents a three-dimensional system that imitates the normal endometrium.

\section{Introduction}

Several culture systems have been used to study various aspects of mammalian endometrial metabolism (for review, see Findlay et al., 1990) and embryo-endometrial interactions (Lindenberg et al., 1985). However, none of these culture systems in vitro fully imitates the normal structure and function of the endometrium in vivo (Hearn, 1986).

Previous studies on endometrial epithelial monolayers in contact with the human embryo (Lindenberg et al., 1985) have given information only about the attachment of the embryo. As normal implantation is considered to be an active process involving both trophoblastic cells and cells of the secretory endometrium, it is questionable whether observations on 'in vitro implantation' reflect the true situation in vivo.

Endometrial stroma cells influence the development of epithelial cells (Mahfoudi et al., 1992) and may, alone or together with the extracellular matrix, play an important role in implantation. A possible significance of the extracellular matrix in implantation comes from a preliminary study in which human blastocysts were co-cultured on human endometrial epithelial cells supported by an extracellular matrix in vitro (B. Pedersen, A. Philip and S. Lindenberg, unpublished).

The object of this study was to establish a model in vitro that imitates the normal human secretory endometrium in vivo.

Received 11 October 1993.
The model consisted of polarized epithelial cells resting on an artificial basement membrane (Matrigel), with underlying stromal cells embedded in a collagen matrix.

\section{Materials and Methods}

\section{Isolation of tissues}

Endometrial tissues were obtained by curettage (Cunell biopsy) from 12 normal ovulating women admitted to our department for tubal sterilization. The biopsies, 6-8 per patient, were taken at 3-14 days after the occurrence of the endogenous LH peak. All biopsies used were histologically classified as normal endometrium corresponding to the measured LH peak (Johannisson et al., 1982, 1987; Li et al., 1988).

Biopsy material from each patient was processed for light and electron microscopy and for immunohistochemistry (see below). One biopsy was frozen for further studies, and the remaining material was used for cell culture.

The study was approved by the National Ethical Committee (Denmark) and the women had signed informed consent forms.

\section{Preparation of endometrial cultures}

Tissue samples (approximately $30 \mathrm{mg}$ wet mass) were transferred to flasks containing Ham's F-10 medium (Nutrient 
mixture F-10: GIBCO, Life Technologies, Roskilde), supplemented with $0.2 \%$ penicillin-streptomycin $\left(10000 \mathrm{iu} \mathrm{ml}^{-1}\right.$; GIBCO). After washing, the tissue was minced into small pieces with a scalpel and incubated in $5 \mathrm{ml}$ trypsin-EDTA ( $1 \times$ trypsin-EDTA solution; GIBCO), and supplemented with $0.05 \mathrm{~g}$ pancreatin $\mathrm{ml}^{-1}$ (Sigma Chemical Co, St Louis, MO) for $30 \mathrm{~min}$ at $4^{\circ} \mathrm{C}$. This incubation was continued at room temperature in a Petri dish and the detachment of the glands and surface epithelium was carefully followed through a stereo microscope. The large epithelial glands and surface epithelium were sampled with a pipette into Ham's F-10 medium, sedimented at $60 \mathrm{~g}$ for $10 \mathrm{~min}$ and resuspended in Ham's F-10 medium. After this sampling the remaining 'stromal cell fraction' was supplemented with $5 \mathrm{ml}$ fetal calf serum (GIBCO) to stop the enzyme digestion. After sedimentation, the supernatant was removed with a pipette and sedimented at $60 \mathrm{~g}$ for $10 \mathrm{~min}$. The resulting pellet was treated with $150 \mathrm{iu}$ collagenase $\mathrm{ml}^{-1}$ (Sigma) for $45 \mathrm{~min}$ at $37^{\circ} \mathrm{C}$ to obtain a single cell suspension. After sedimentation at $60 \mathrm{~g}$ for $10 \mathrm{~min}$, the cells were washed in Ham's F-10 and the two cell fractions could be seeded. The 'stromal cell fraction' was sedimented at $60 \mathrm{~g}$ for $10 \mathrm{~min}$ and the pellet was mixed with Vitrogen 100 (Celtrix Laboratories, Palo Alto, CA), which consisted

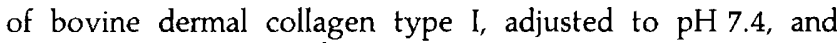
$2.3 \mathrm{mg}$ collagen $\mathrm{ml}^{-1}$. The final cell concentration was $2-10 \times 10^{6}$ cells ml $^{-1}$, and $300 \mu \mathrm{l}$ of the mixture was placed in a Falcon Cell Culture insert $9 \mathrm{~mm}$ in diameter (Becton Dickinson, NJ).

The inserts were placed in six-well culture dishes (Nunclon multidish 6 wells Delta SI: NUNC A/S, Roskilde). The collagen gel was allowed to polymerize for $45 \mathrm{~min}$ at $37^{\circ} \mathrm{C}$, after which the upper surface was coated with a thin layer of murine basement membrane material (Matrigel: Collaborate Research Inc, Bedford, MA). Matrigel was diluted 1:1 (v:v) with Alpha Modification of Eagle's medium (Flow Laboratories, Irvine) and $500 \mu \mathrm{l}$ was applied to the surface for $30 \mathrm{~s}$. The suspension was then removed with a pipette and $3 \mathrm{ml}$ culture medium was added to the bottom of the six-well dishes. After an additional $30 \mathrm{~min}$ at $37^{\circ} \mathrm{C}$ the 'epithelial gland fraction' was seeded on top of the artificial basement membrane and $400 \mu \mathrm{l}$ culture medium was added into the cell culture insert. The optimal seeding density was achieved when the glands covered approximately $20 \%$ of the surface, allowing them to explant in a monolayer. Usually the cultures were confluent after 3 days. On average, six cultures per patient were established from the $30 \mathrm{mg}$ tissue extracted; the number of stromal cells was the limiting factor.

\section{Culture conditions}

The culture medium used was Alpha Modification of Eagle's medium (Flow Laboratories); $100 \mathrm{ml}$ were supplemented with $0.2 \mathrm{ml}$ penicillin-streptomycin (10000 iu ml ${ }^{-1}$, GIBCO), $0.5 \mathrm{ml} \mathrm{L}$-glutamine $\left(200 \mathrm{mmol}^{-1}, \mathrm{GIBCO}\right), 2 \mathrm{ml}$ Ultroser $\mathrm{G}$ (IBF-Biotechnics, Villeneuve-la-Garenne), $5 \mathrm{ml}$ fetal calf serum (GIBCO), $0.5 \mathrm{~g}$ BSA (Behring Institut, Marburg), $10 \mu \mathrm{g}$ retinoic acid (Sigma) and $1.75 \mu \mathrm{g}$ progesterone. Since oestradiol concentration in the medium was already $35 \mathrm{nmol} \mathrm{I}^{-1}$, it was not supplemented with oestrogen.
All cultures were maintained in a humidified atmosphere with $5 \% \mathrm{CO}_{2}$ in air and the medium was changed the day after seeding and then every other day. The cultures were examined under a Zeiss inverted phase contrast microscope.

\section{Preparation for electron microscopy}

For transmission electron microscopy and scanning electron microscopy, the cultures and fresh biopsied material were fixed in Karnovsky's fixative (Karnovsky, 1965) in a sodium cacodylate buffer $\left(0.1 \mathrm{~mol} \mathrm{1}^{-1}, \mathrm{pH} 7.2\right.$; Merck, Darmstadt) for $60 \mathrm{~min}$ at $20^{\circ} \mathrm{C}$.

For transmission electron microscopy, the cultures and fresh biopsied material were washed in $0.1 \mathrm{~mol}$ phosphate buffer $1^{-1}, \mathrm{pH} \mathrm{7.4}$, and fixed in $1 \%$ osmium tetroxide in $0.1 \mathrm{~mol}$ sodium cacodylate $1^{-1}$ buffer for $2 \mathrm{~h}$ at $5^{\circ} \mathrm{C}$. Subsequently, they were dehydrated and embedded in Epon (Merck). The embedded cultures and biopsies were sectioned into semi-thin and ultra-thin sections. Semi-thin sections were stained with toluidine blue, while ultra-thin sections were contrasted with uranyl acetate and lead citrate and examined under a Jeol JEM $100 \mathrm{~B}$ electron microscope.

For scanning electron microscopy, the cultures and fresh biopsied material were washed in phosphate buffer, fixed in osmium tetroxide and dehydrated in graded ethanols. After drying to the critical point, the specimens were sputter-coated with gold and examined under a Jeol 25 SII microscope at $25 \mathrm{kV}$.

\section{Preparation for light microscropy and immunohistochemistry}

The cultures and fresh biopsied material were fixed in neutral-buffered $4 \%$ formaldehyde for $30 \mathrm{~min}$ at $4^{\circ} \mathrm{C}$ and dehydrated. The material was embedded in paraffin wax and cut to $5 \mu \mathrm{m}$ sections. For light microscopy the sections were stained with haematoxylin-eosin. For immunohistochemistry (cultures only) a three-stage immunoperoxidase-staining procedure was used to demonstrate the presence of cytokeratin and human collagen IV. Endogenous peroxidase was inhibited by incubating the slides with $1 \%$ hydrogen peroxide in distilled water for $5 \mathrm{~min}$. They were then washed in $0.05 \mathrm{~mol}$ Tris $-\mathrm{HCl}$ $1^{-1}$ buffer, pH 7.6. Sections were pretreated with $0.2 \mathrm{mg}$ trypsin $\mathrm{ml}^{-1}$ (Sigma) for $10 \mathrm{~min}$ at $37^{\circ} \mathrm{C}$. After incubation in normal swine serum (DAKO, Glostrup) that had been diluted 1:5 (v:v) in Tris buffer for $20 \mathrm{~min}$ at room temperature, the sections were incubated with monoclonal antibodies against collagen IV (mouse anti-human collagen IV, Dako) at a concentration of $1: 50(\mathrm{v}: \mathrm{v})$ or cytokeratin (mouse anti-human cytokeratin, Dako) at a concentration of 1:10 (v:v) overnight at $4^{\circ} \mathrm{C}$. Both antibodies were diluted in Tris buffer. Sections were then overlayered with rabbit anti-mouse immunoglobulin/ horseradish peroxidase (Dako) diluted 1:100 (v:v) in Tris buffer for $30 \mathrm{~min}$ at room temperature, followed by washing twice for $5 \mathrm{~min}$ each in Tris buffer. The last step was an incubation with swine anti-rabbit immunoglobulin/horseradish peroxidase (Dako) diluted 1:100 (v:v) in Tris buffer for 30 min followed by washing twice in Tris buffer for $5 \mathrm{~min}$.

Negative controls were processed simultaneously by omitting the primary antibody; positive controls were skin. 

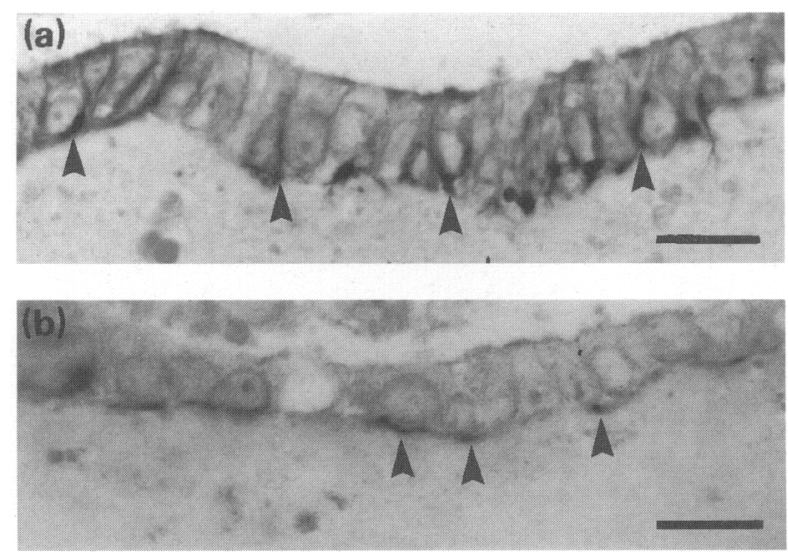

(c)

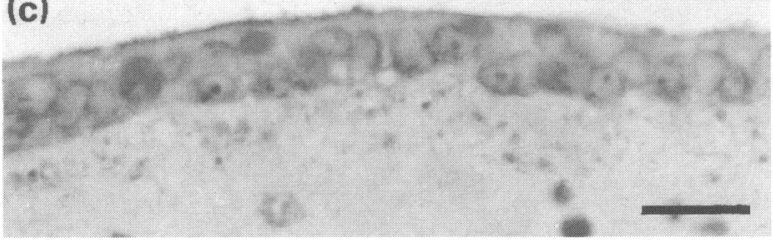

Fig. 1. Light micrograph of histochemically stained cultured cells. (a) Positive cytokeratin staining (arrowheads) concentrated at the cell borders of the epithelium confirms the epithelial origin of these cells. (b) Staining for human collagen IV indicates its presence underneath the epithelial cells (arrowheads). (c) Negative control cultured cells were not stained. (Scale bar represents $30 \mu \mathrm{m}$.)

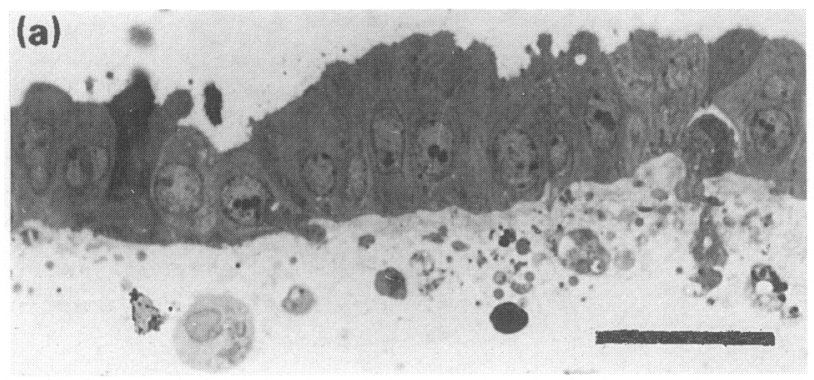

(b)

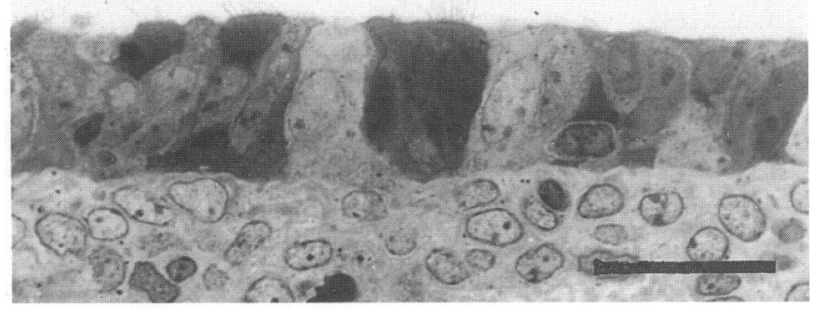

Fig. 2. Light micrograph showing (a) cultured polarized epithelial cells on the surface and stromal cells embedded in the collagen gel after culture for 4 days. The density of the stromal cells is lower than in (b) the biopsy material. The stain is toluidine blue. (Scale bars represent $15 \mu \mathrm{m}$.)

B 006 (Monocarb A/B, Lund) was used to detect nonspecific binding. Antibody binding was visualized using 3-amino-9ethylcarbazole (Sigma) dissolved in acetone and $0.05 \mathrm{~mol}$
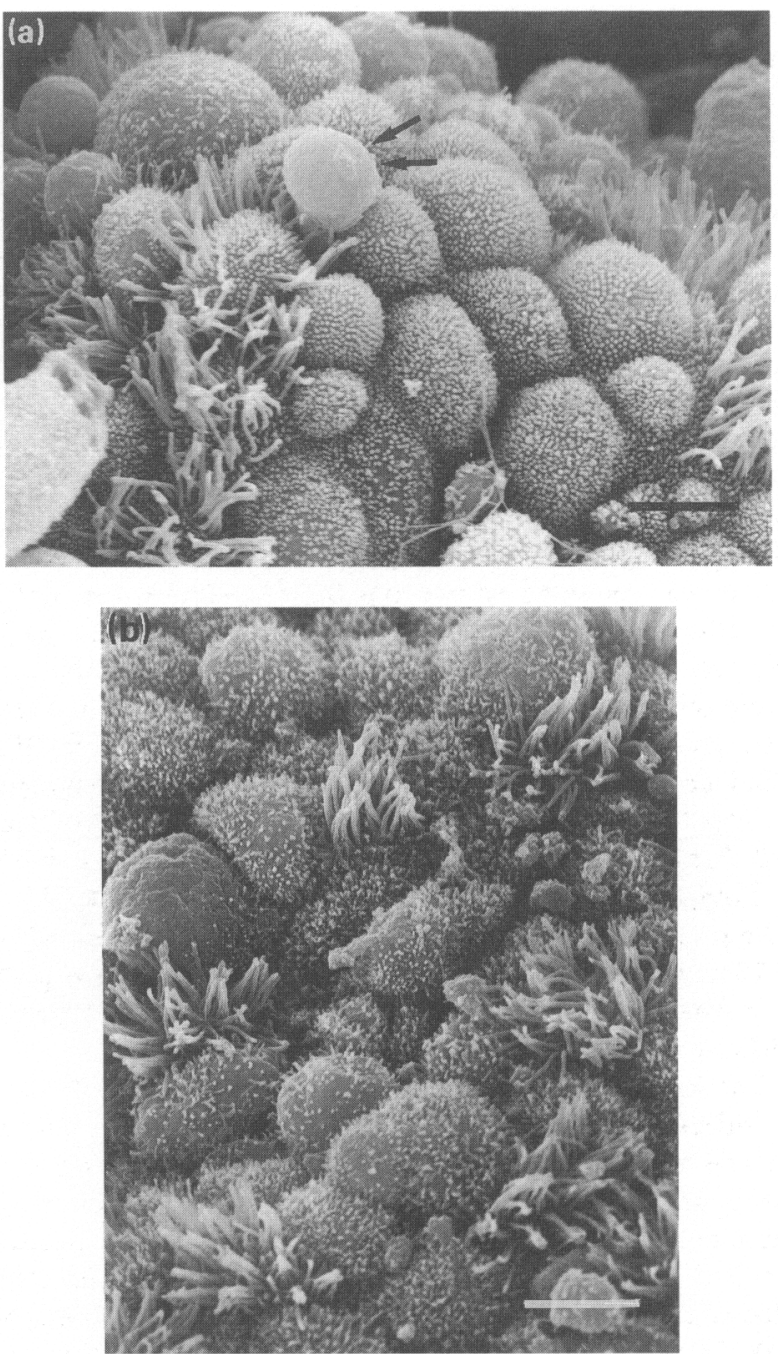

Fig. 3. (a) Scanning electron micrograph of cultured epithelial cells. Note the abundance of microvilli and cilia formation. Arrows indicate a pinopode. (b) Scanning electron micrograph of epithelial cells in a biopsy. (Scale bars represent $10 \mu \mathrm{m}$.)

acetate buffer $\mathrm{l}^{-\mathfrak{l}}, \mathrm{pH} 5.0$, for 9 min. After rinsing in distilled water the nuclei were counterstained with Mayers haematoxylin (Merck) for $5 \mathrm{~min}$. The sections were mounted in Glycergel (Dako).

\section{Results}

All biopsy specimens were evaluated by light microscopy and by transmission and scanning electron microscopy. The number of culture wells established from the biopsies of each of 12 patients was between 2 and 12 . All cultures were examined using an inverted microscope with phase contrast, and confluent cultures from each patient were examined by transmission and scanning electron microscopy or immunohistochemistry. Altogether, 27 cultures were prepared for transmission electron microscopy, at least one per patient, and four cultures from four different patients for scanning electron microscopy. Twenty-four cultures, at least one per patient, 

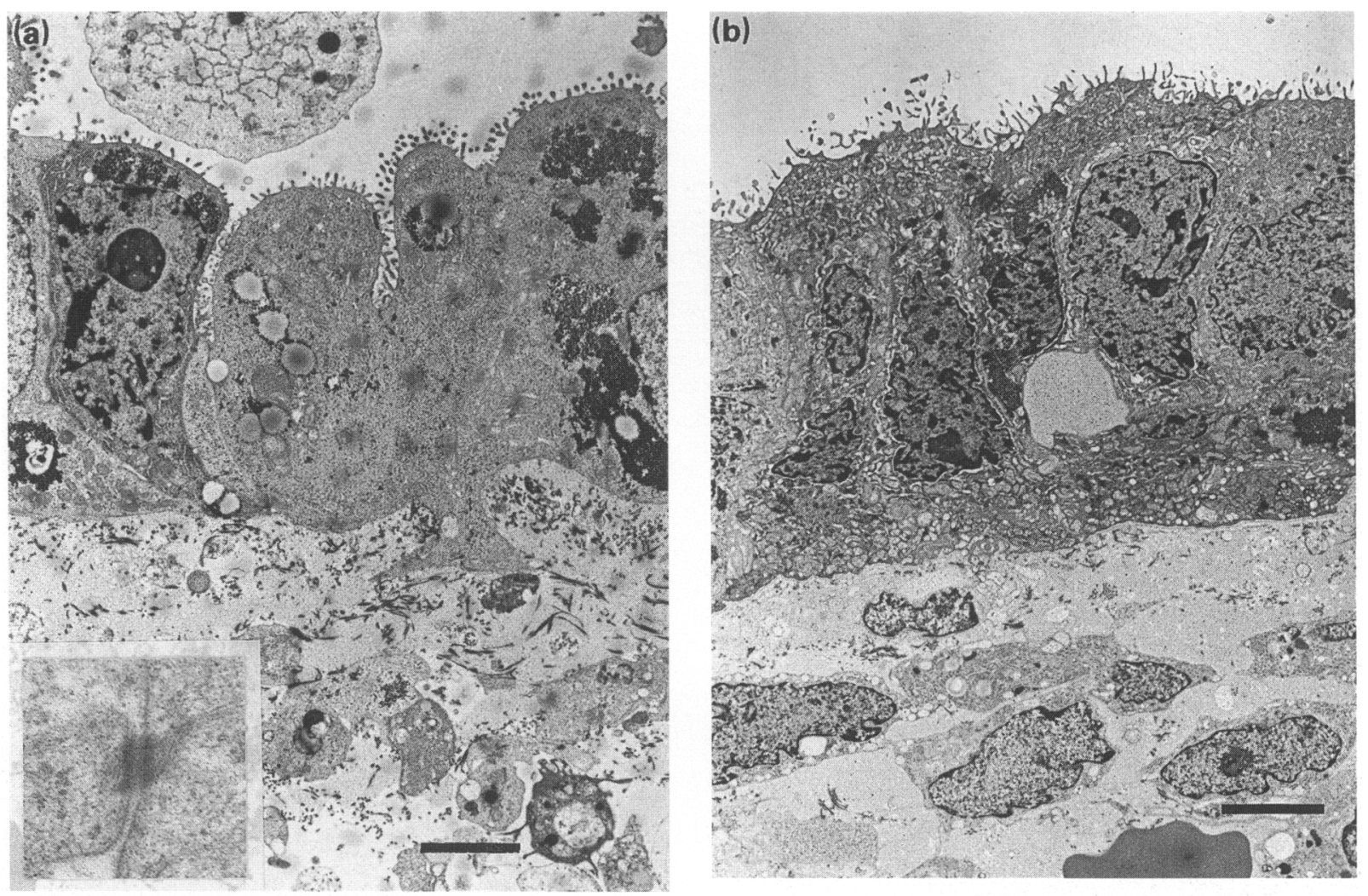

Fig. 4. (a) Transmission electron micrograph of cells cultured for 3 days. An epithelial monolayer was placed on top of the stromal compartment. The epithelial cells are polarized, with microvilli on the surface, apical desmosomes (see insert) and well-developed intracellular glycogen deposits. The stromal cells were placed underneath the basement membrane material. (b) Transmission electron micrograph of surface epithelium and stroma in a biopsy. (Scale bar represents $3.3 \mu \mathrm{m}$.)

were embedded in paraffin wax for immunohistochemistry. Fifteen non-confluent or very shrunken cultures were omitted from the study.

\section{Immunohistochemistry}

Cytokeratin was detected in epithelial cells (Fig. Ia) concentrated at the cell borders, whereas cells beneath the basement membrane did not stain for cytokeratin. Staining for human collagen type IV demonstrated its presence underneath the epithelium (Fig. 1b). Matrigel is of murine origin and did not stain with this antibody. Negative controls were unstained (Fig. 1c).

\section{Morphology}

Light microscopy. The epithelial compartment of the cell cultures comprised polarized columnar cells with basally located nuclei (Fig. 2a). The stromal cells were distributed just beneath the epithelium, whereas the deeper part of the Vitrogen contained very few cells. Occasional gland formation was detected. Morphological resemblance between cultured and biopsied material (Fig. 2b) was demonstrated, but the cell cultures contained fewer stromal cells and showed no sign of capillary formation.
Scanning electron microscopy. The cultured epithelium was confluent and revealed an abundance of both cilia and microvilli. Pinopodes were seen (Fig. 3a). There were similarities between the cultured (Fig. 3a) and the biopsied material (Fig. 3b).

Transmission electron microscopy. The polarization of the cultured epithelium was confirmed, and the nuclei of the epithelial cells were located basally, similar to the biopsied material (Fig. 4a,b). The surface of both cultured and biopsied epithelial cells was covered with numerous slender microvilli (Fig. $4 a, b$ ). The cells were attached to each other by desmosomes (Fig. 4a, insert). The cytoplasm of both cultured and biopsied cells contained various amounts of glycogen and a well-developed organelle apparatus. The cells contained long, slender mitochondria in close association with rough endoplasmic reticulum, polyribosomes and glycogen deposits in the basal compartment (Fig. 5).

At the interface between the epithelium and stroma, a discontinuous basal lamina was observed (Fig. 6), and collagen was detected underneath the basement membrane, as well as in stromal protrusions in close association with the basal surface of the epithelial cells (Fig. 5).

The density of the stromal cells was less pronounced in the cultures (Fig. 4a,b). The stromal cells were rich in rough endoplasmic reticulum and polyribosomes (Figs 5 and 7), and 


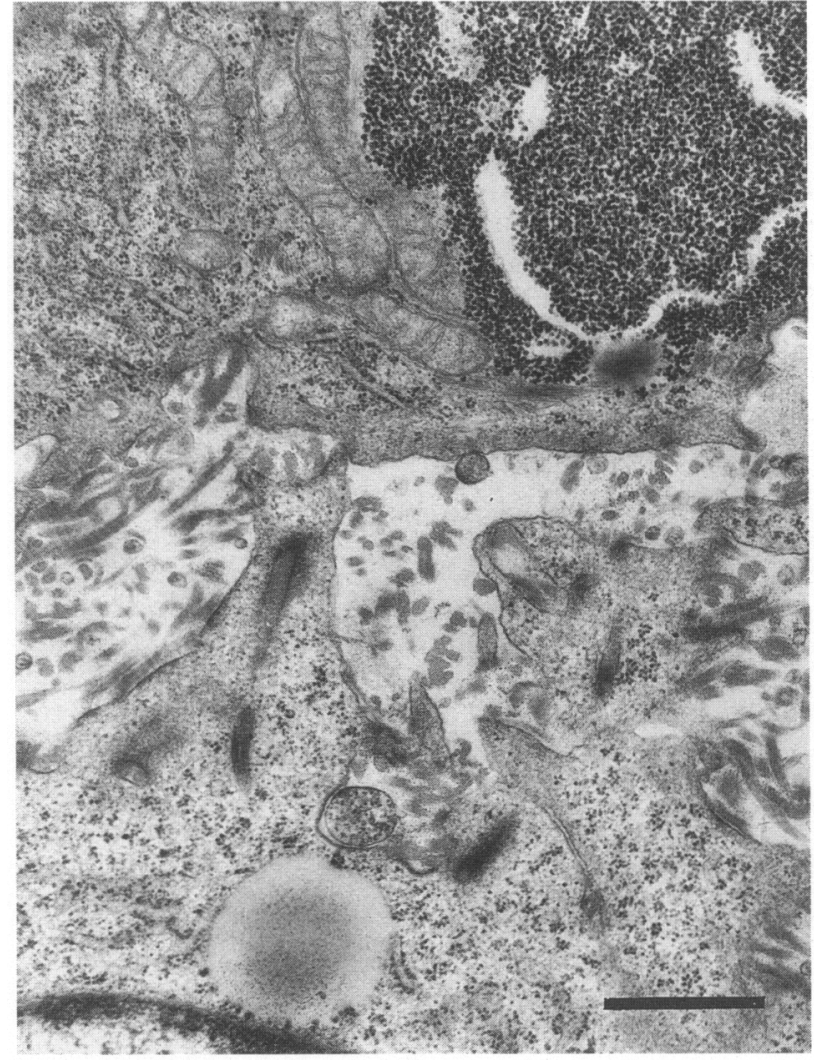

Fig. 5. Transmission electron micrograph of cultured cells: a stromal cell (bottom) is in close association with the basal surface of an epithelial cell (top). The cytoplasm of the epithelial cell contains glycogen, long slender mitochondria, rough endoplasmic reticulum and polyribosomes. Note the collagen beneath the epithelial compartment. The cytoplasm of the stromal cell contains polyribosomes and rough endoplasmic reticulum. (Scale bar represents $1 \mu \mathrm{m}$.)

contained only small amounts of glycugen and microfilaments in various amounts along cell borders.

\section{Discussion}

In mammals, blastocyst implantation is the process by which the fertilized ovum, which has developed to the hatched blastocyst stage, becomes intimately connected to the maternal tissue in the uterus. Since this process requires interactions between the embryo and the maternal tissue, it is useful to separate the events of implantation into several phases (Larsen, 1974; Schlafke and Enders, 1975). The study of these early stages of human implantation in vivo is for practical purposes impossible; several culture systems in vitro have therefore been developed.

In early experiments Gwatkin (1966) permitted a murine blastocyst to attach to plastic in order to determine culture requirements. Glenister (1961) and Grant et al. (1975) examined blastocyst implantation on rabbit endometrial strips and cultured murine uteri, allowing the blastocyst to penetrate the epithelium and basement membrane. However, necrosis meant that these culture systems were of no value. Lindenberg $e t$ al.

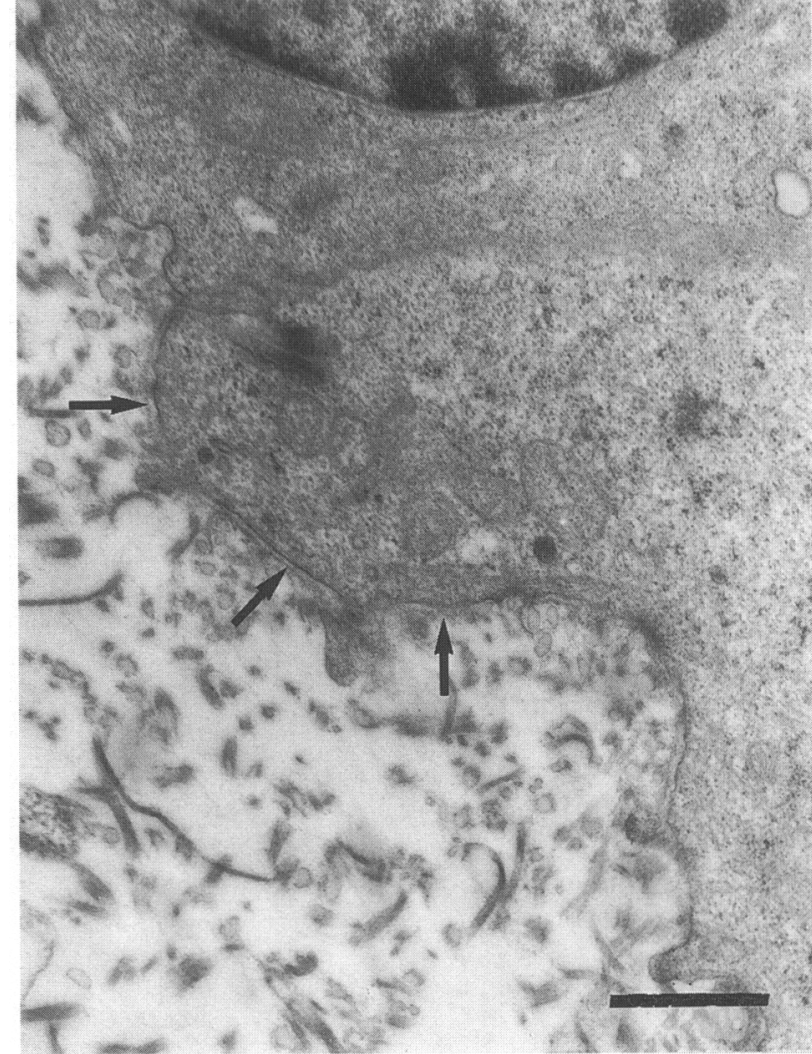

Fig. 6. Transmission electron micrograph of basal lamina (arrows) underneath an epithelial cell. (Scale bar represents $1 \mu \mathrm{m}$.)

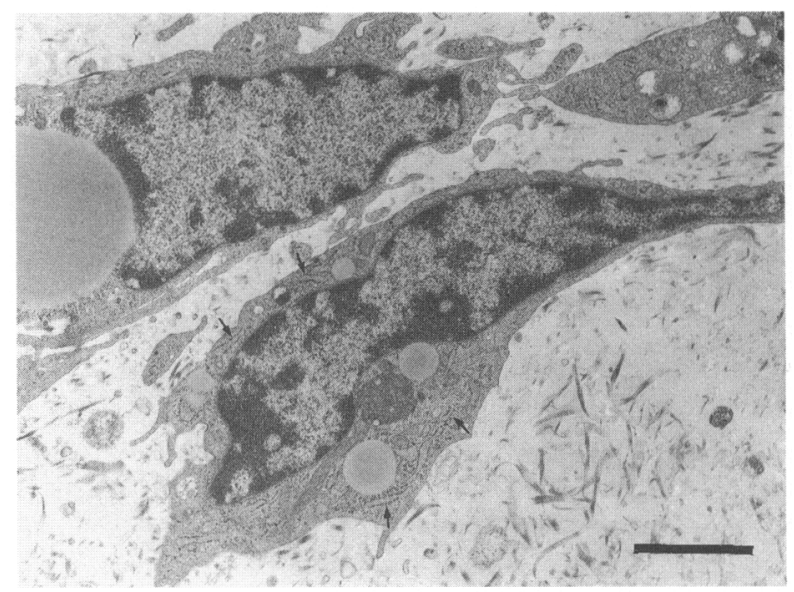

Fig. 7. Transmission electron micrograph of cultured stromal cells The cells are not polarized and the cytoplasm is rich in slightly dilated rough endoplasmic reticulum (arrows) and polyribosomes. (Scale bar represents $2 \mu \mathrm{m}$.)

(1984) made similar observations when culturing human endometrial tissue.

Studies of trophoblast interactions with isolated components of the endometrium, such as stromal cells (Salomon and Sherman, 1975), basement membrane material (Armant et al., 1986a,b) or extracellular matrix (Farach et al., 1987), or interactions with cultured murine epithelial monolayers gave only 
limited information (Van Blerkom and Chavez, 1981). A technique by which human endometrial epithelial monolayers were cultured on plastic was developed by Lindenberg et al. (1984). This system was suitable for studying apposition and attachment of human blastocysts to epithelial cells (Lindenberg et al., 1985), but provided no information about further stages of the implantation process.

We modified the model (Lindenberg et al, 1984) to examine trophoblast attachment to, and penetration through, the epithelial layer and interaction with the extracellular matrix and stromal cells. In a preliminary series of experiments (B. Pedersen, A. Philip and S. Lindenberg, unpublished), human endometrial epithelial cells were cultured on a collagen membrane and a hatched blastocyst was attached to the monolayer. This in vitro system was extended into a co-culture system, including stromal cells, that was embedded in a collagen matrix and separated from the epithelial monolayer by a basement membrane material, Matrigel, that was extracted from Engelbreth Holm Swarm mouse tumours (Kleinman et al., 1986). Matrigel has been demonstrated to promote a differentiated morphology of the endometrial epithelial cells in primary culture (Mahfoudi et al., 1992).

To study implantation, it is important to have a polarized epithelium with well-developed intercellular junctions that rests on a basement membrane. Furthermore, it is crucial to have a three-dimensional stromal compartment with both extracellular matrix and stromal cells, since interaction(s) between epithelium and the underlying stromal cells is (are) essential for the function of the endometrium (Inaba et al., 1988). It has been reported that the stroma may mediate oestrogen responsiveness in cultured murine uterine epithelia (Inaba et al., 1988).

In the present culture system the epithelial compartment was derived from glandular and surface epithelial cells. Human collagen IV was observed underneath the epithelial cells (Fig. Ib) showing cell polarization and indicating that the present culture model is a dynamic system. Although deposition of basement membrane, as revealed by transmission electron microscopy, could not be demonstrated initially (after 3 days) it did appear later, giving further support to the contention that this culture system is a dynamic environment. However, a prolonged culture time resulted in considerable shrinkage of the gel, which could be due to release of proteolytic enzymes by the cells.

The present culture system seems to fulfil the morphological three-dimensional criteria for an implantation system by presenting a polarized epithelium resting on a basement membrane, with an underlying collagen matrix containing stromal cells.

The authors thank $U$. Howitz for technical assistance with the cell cultures, S. Sorensen and K. Kjeldsen for excellent work with preparations for electron microscopy. This study was supported by the Danish Medical Research Foundation, Haench's Foundation and Vera og Carl Johan Michaelsens Foundation.

\section{References}

Armant DR, Kaplan HA and Lennarz WJ (1986a) Fibronectin and laminin promote in vitro attachment and outgrowth of mouse blastocysts Developmental Biology $116519-523$

Armant DR, Kaplan HA, Mover H and Lennarz WJ (1986b) The effect of hexapeptides on attachment and outgrowth of mouse blastocysts cultured in vitro: Evidence for the involvement of the cell recognition tripeptide Arg-Gly-Asp Proceedings of the National Academy of Sciences USA 83 $6751-6755$

Farach MC, Tang JP, Decker GL and Carson DD (1987) Heparin/heparan sulfate is involved in attachment and spreading of mouse embryos in vitro Developmental Biology 123 401-410

Findlay JK, Salamonsen LA and Cherny RA (1990) Endometrial function: studies using isolated cells in vitro Oxford Reviews of Reproductive Biology 12 181-223

Glenister TW (1961) Observations on the behaviour in organ culture of rabbit trophoblast from implanting blastocysts and early placentae Journal of Anatomy 95 474-484

Grant PS, Ljungkvist I and Nilsson $O$ (1975) The hormonal control and morphology of blastocyst invasion in the mouse uterus in vitro Joumal of Embryology and Experimental Morphology 34 299-344

Gwatkin RBL (1966) Amino acid requirements for attachment and outgrowth of the blastocyst in vitro Joumal of Cellular Physiology 68 335-344

Hearn JP (1986) The embryo-matemal dialogue during early pregnancy in primates Journal of Reproduction and Fertility 76 809-819

Inaba T, Wiest WG, Strickler RC and Mori J (1988) Augmentation of the response of mouse uterine epithelial cells to estradiol by uterine stroma Endocrinology 123 1253-1258

Johannisson E, Parker RA, Landgren B-M and Diczfalusy E (1982) Morphometric analysis of the human endometrium in relation to peripheral hormone levels Fertility and Sterility 38 564-57I

Johannisson E, Landgren B-M, Rohr HP and Diczfalusy E (1987) Endometrial morphology and peripheral hormone levels in women with regular menstrual cycles Fertility and Sterility $\mathbf{4 8} 401-408$

Karnovsky MJ (1965) A formaldehyde-glutar-aldehyde fixative of high osmolarity for use in electron microscopy Journal of Cell Biology $27137 \mathrm{~A}$

Kleinman HK, McGarvey ML, Hassell JR, Star VL, Cannon FB, Laurie GW and Martin GR (1986) Basement membrane complexes with biological activity Biochemistry 25 312-318

Larsen JF (1974) Ultrastructural studies of the implantation process Basic Life Science 4 (PT.B) 287-296

Li TC, Rogers AW, Dockery P, Lenton EA and Cooke ID (1988) A new method of histologic dating of human endometrium in the luteal phase Fertility and Sterility $5052-60$

Lindenberg S, Lauritsen JG, Nielsen MH and Larsen JF (1984) Isolation and culture of human endometrial cells Fertility and Sterility 41 650-652

Lindenberg S, Nielsen MH and Lenz S (1985) In vitro studies of human blastocyst implantation Annals of the New York Academy of Science 42 368-374

Malfoudi A, Fauconnet S, Bride J, Beck L, Remy-Martin J-P, Nicollier M and Adessi GL (1992) Serum-free culture of stromal and functionally polarized epithelial cells of guinea-pig endometrium: a potential model for the study of epithelial-stromal paracrine interactions Biology of the Cell $\mathbf{7 4}$ 255-265

Salomon DS and Sherman MI (1975) Implantation and invasiveness of mouse blastocysts on uterine monolayers Experimental Cell Research 90 261-268

Schlafke S and Enders AC (1975) Cellular basis of interaction between trophoblast and uterus implantation Biology of Reproduction 12 41-65

Van Blerkom J and Chavez DJ (1981) Morphodynamics of outgrowth of mouse trophoblast in the presence and absence of a monolayer of uterine epithelium American Joumal of Anatomy 162 143-155 